\title{
Equivalent Modeling of Double-fed Wind Farm Based on Flow Field Characteristics
}

\author{
http://dx.doi.org/10.3991/ijoe.v10i6.3967 \\ Gu Bo, Hu Hao, Huang Hui and Liu Xinyu \\ North China University of Water Resources and Electric Power, Zhengzhou, China
}

\begin{abstract}
At present, the entire wind farm is regarded as a large-capacity wind turbine for modeling double-fed wind farm. The influence of flow field characteristics in the wind farm has been ignored. In order to reflect the influence in double-fed wind farm equivalent modeling, an equivalent modeling method of double-fed wind farm based on the flow field characteristics has been proposed. A calculation model of the double-fed wind farm flow field has been built considering the influence of terrain and wake. The wind speed was calculated at each wind turbine installed point based on the flow field calculation model, and using the wind speed as the input wind speed for each wind turbine, the dynamic characteristics of the wind farm production process has been studied. The simulation analysis has been done for the proposed modeling method, and the simulation results show that the proposed modeling method can reflects the dynamic characteristics of the wind farm production process more accurately.
\end{abstract}

Index Terms-Double-fed wind farm, Equivalent modeling, Wake effect, Flow field characteristics, Dynamic characteristics

\section{INTRODUCTION}

Because a series of serious environmental events, such as haze invasion and PM2.5 index explosion, etc, wind energy as a renewable and non-polluting energy has been paid increasing attention and developed rapidly [1-2]. Equivalent modeling for the wind farm is the foundation for studying wind farm grid integration. With the large scale wind farms connected with power grid in succession, the key problem needing to be resolved urgently is that establishing the equivalent model reflecting the wind farm real production process. At present, the equivalent modeling method for wind farm is that the wind turbines in the wind farm are equal as weighted single machine model, and ignoring the flow field information of the wind farm. This modeling method has a deviation when researching the production process dynamic characteristics of the grid connected wind farm.

Part of wind energy can be transformed into mechanical energy by wind turbine to drive the generator work, so the wind speed will be reduced when the wind passes by wind turbine. Due to the different location of wind turbines in the wind farm, the wind speed of wind turbines located downwind significantly lower than upwind ones[3], which it's known as wake effects, and the wind energy loss caused by this effects will directly affect the economic benefits of wind power field. The wind farm operating experience in California shows that according to the different topography and geomorphology, the distance and wind turbulence intensity between each turbine, the mini- mum of wake loss is $2 \%$ while the maximum can amount to $30 \%$ [4]. When ignoring the actual location of wind turbines and the wake effects between each turbine, the entire wind farm can be equivalent to a single model, and this method couldn't reflects the dynamic characteristics in wind farm production process[5]. A modeling method based on genetic algorithm of the single turbine equivalent model for wind farm has been proposed [6]. Compared with the weighted single turbine equivalent model of wind farm, this method can better reflect the wind farm operation characteristics, but ignored the flow field information of wind farm. A new equivalent modeling method has been proposed based on auto mutation particle swarm optimization algorithm for double-fed wind turbines [7]. In this method, wind turbines are classified into different classification according to the wind turbine type, and its equivalent model is obtained by simplifying the control strategy. This method is applicable to the analysis and calculation for the large-scale wind farm integration.

Above wind farm modeling method does not consider the effect of the flow field characteristics, which influenced the study of dynamic characteristics of wind farm. Therefore, an equivalent modeling method of double-fed wind farm based on the flow field characteristics has been proposed in this paper. The calculation model of the double-fed wind farm flow field has been built considering the influence of terrain and wake. The wind speed was calculated at each wind turbine installed point based on the flow field calculation model, and using the wind speed as the input wind speed for each wind turbine, the dynamic characteristics of the wind farm production process has been studied. The simulation analysis has been done for the proposed modeling method.

\section{THE FlOW FIELD CHARACTERISTICS OF WIND FARM}

\section{A. The natural wind speed}

The neural wind speed can be calculated by equation (1).

$$
\left\{\begin{array}{l}
U=\bar{U}(z)+u(y, z, t) \\
v=v(y, z, t) \\
w=w(y, z, t)
\end{array}\right.
$$

In the equation (1), $\overline{\mathrm{U}}(\mathrm{z})$ is the longitudinal average wind velocity of a point in the flow field; $u$ is the longitudinal turbulent wind velocity; $\mathrm{v}$ is the lateral turbulent wind velocity; and $w$ is the vertical turbulent wind velocity.

Under the condition of neutral atmosphere, regardless of the Coriolis Effect, the longitudinal average wind velocity $\bar{U}(\mathrm{z})$ can be calculated by equation (2). 


$$
\overline{\mathrm{U}}(\mathrm{z})=\frac{\mathrm{u}_{*}}{\mathrm{k}} \ln \left(\mathrm{z} / \mathrm{z}_{0}\right)
$$

In the equation (2), $\mathrm{u}_{*}$ is the friction velocity; $\mathrm{k}$ is the von Karman's constant; $z_{0}$ is the surface roughness. Under the condition of neutral atmosphere, the value of $\mathrm{k}$ is 0.4 .

\section{B. The single wind turbine wake model}

Figure 1 is the schematic diagram of the fluid flowing through the single wind turbine. $U_{0}$ is the velocity of the free wind speed, $D_{0}$ is the rotor diameter of the wind turbine, $A$ is the wake region area at a distance of $x$ after the turbine, $\mathrm{U}$ is the wake speed at this wake region. Assuming there is a cylinder on the outside of the wind turbine streamline, as the dotted line shows in Figure 1, $V$ is the volume of the cylinder, $A_{T}$ is the surface area of cylinder. For the cylinder, there is only the inlet and the outlet planes of the cylinder interaction with the outside fluid, other planes without any interact with the outside fluid.

Inside the cylinder, the equation (3) can be derived from conservation of linear momentum.

$$
\int_{V} \rho \frac{\partial \vec{U}}{\partial t} d V+\int_{A_{T}} \rho \vec{U}(\vec{U} d \vec{A})=-\int_{A_{T}} p d \vec{A}+\int_{V} \rho \vec{g} d V+\vec{T}+\int_{A T} \vec{\tau} d \vec{A}
$$

Assuming the cylinder is sufficiently long, so the inlet plane and outlet plane are in a steady state with the outside flow field. When the wind speed is lower than that of $100 \mathrm{~m} / \mathrm{s}$, air flow can be assumed inviscid flow, in equation (3), the calculation results of the first item on the left, and the first item, the second item and the fourth item on the right are zero, the equation (3) can be simplified to equation (4).

$$
T=\int_{A} \rho U\left(U_{0}-U\right) d A=\rho U\left(U_{0}-U\right) A
$$

According to the aerodynamic principle, the thrust acting on the wind turbine can be expressed as equation (5).

$$
T=\frac{1}{2} \rho A_{0} U_{0} C_{T}
$$

In equation (5), $A_{0}$ is the swept area of wind turbine, $C_{T}$ is the thrust coefficient of wind turbine. The equation (6) can be derived according to equation (4) and (5).

$$
\frac{A}{A_{0}}=\frac{1-a / 2}{1-a}
$$

The relationship between the axial induction factor and thrust coefficient can be expressed as equation (7).

$$
C_{T}=a(2-a) \Rightarrow a=1-\sqrt{1-C_{T}}
$$

The relationship between the cross-sectional area in wake and swept area of wind turbine can be expressed as equation (8) according to equation (4) and (5).

$$
A=\beta A, \quad \beta=\frac{1}{2} \frac{1+\sqrt{1-C_{T}}}{\sqrt{1-C_{T}}} \Rightarrow D=\sqrt{\beta} D_{0}
$$

It is can be known from the equation (8) that the expansion of the wake region is a non-linear variation.

According to the equation (4), (5), (6) and (7), the relationship between the wake wind speed and the velocity of the free wind speed can be obtained as equation (9).

$$
\frac{U}{U_{0}}=\frac{1}{2} \pm \frac{1}{2} \sqrt{1-2 \frac{A_{0}}{A} C_{T}}
$$

Because the axial induction factor is always less 0.33 , so the sign "+" does not exist in equation (9). So the equation (10) can be derived.

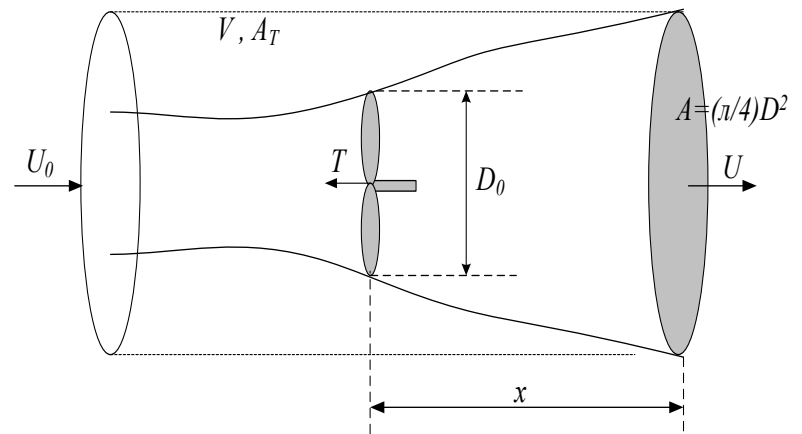

Figure 1. The control body for fluid flowing through the wind turbine

$$
\frac{U}{U_{0}}=\frac{1}{2}+\frac{1}{2} \sqrt{1-2 \frac{A_{0}}{A} C_{T}} \approx 1-\frac{1}{2} \frac{A_{0}}{A} C_{T} \approx 1-a \frac{A_{0}}{A}
$$

The wind tunnel experiment and wind field test have been conducted for the wake in the far wake field [8], the nonlinear change process of the wake radius for far wake field changing with distance has been further amended, then the equation (11) can be obtained.

$$
D(x)=\left(\beta^{\frac{k}{2}}+\alpha s\right)^{\frac{1}{k}} D_{0}, s=x / D
$$

In equation (11), $x$ represents the distance from the wind turbine to downstream and the value of $\alpha$ must be obtained by experiment.

From the reasoning process above, it is known that the change of the radius and the wake region in far wake region are nonlinear and change with the distance. The nonlinear model of the flow velocity and radius for far wake region has been built in this paper according to the equation (10) and (11).

\section{The wake superposition model}

The wind turbines on the downstream are interference with the wake from the wind turbine in different position on the upstream, which form the wake superposition. The wake superposition contains three models which are disjoint, part disjoint, and contain completely, as shown in figure 2 and 3.

According to the wake superposition model provided in paper [9] and the single unit wake model as said above, the formula (12), (13), and (14) can be derived from formula (10) and (11).

$$
\begin{gathered}
U_{j}=U_{i}\left(1-\frac{1}{2} \frac{A_{0}}{A} C_{T}\right)=U_{i}\left(1-\frac{1}{2\left(\beta^{k / 2}+\alpha s\right)^{1 / k}} C_{T}\right) \\
\delta U_{i j}=\left(U_{i}-U_{j}\right) \frac{\text { Aoverlap }}{A o} \\
\delta U_{n}=\sqrt{\sum_{k=1}^{n-1}\left(\delta U_{k}\right)^{2}}
\end{gathered}
$$

In formula (13), $\delta U_{i j}$ stands for the velocity loss of upstream wind turbine $i$ at the downstream wind turbine $j$, $A_{\text {overlap }}$ stands for the area affecting on the downstream wind turbine $j$ from the wake effect of upstream wind turbine $i, A_{0}$ is the swept area of wind turbine on the downstream, $\delta U_{n}$ stands for the wake loss of $n-1$ upstream wind turbines at the $n$-th wind turbine downstream. 


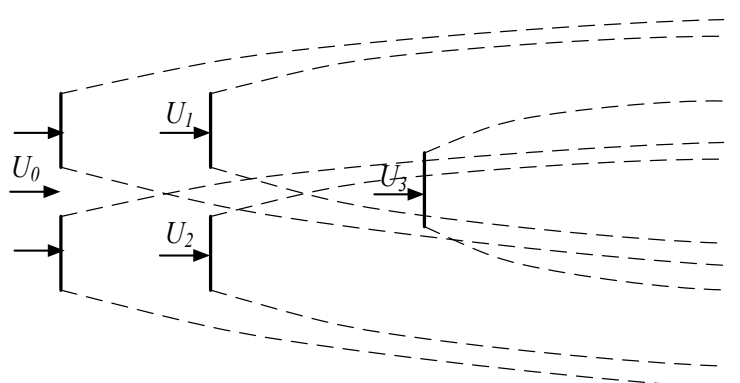

Figure 2. The wind farm wake model

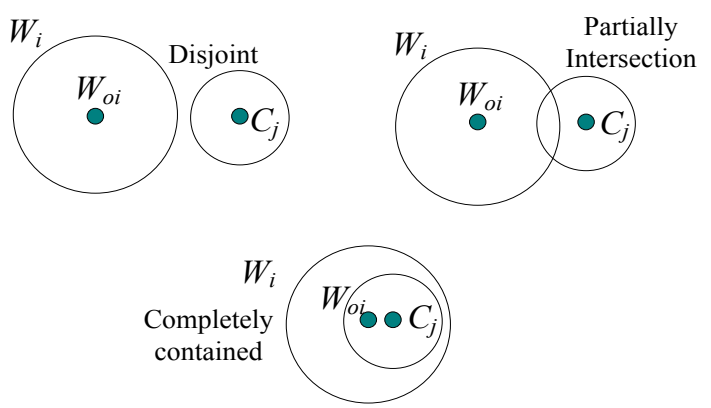

Figure 3. The wake superposition type of wind farm

\section{The AERodynamics Model of Wind Turbine}

The wind energy has been converted into mechanical energy by wind turbines in the process of power generation. According to the Bates theory, the mechanical energy captured from the air by wind turbines can be shown as equation (14).

$$
P=\frac{1}{2} \rho \pi R^{2} v^{3} C_{p}(\lambda, \beta)
$$

In equation (14), $\rho$ is the air density, $R$ is the radius of the wind turbine, $v$ is wind speed, $\beta$ is the pitch angle, $\lambda$ is the tip speed ratio, $C_{p}$ is the power coefficient.

In order to describe the status of the wind turbine's blades in different wind speed, it is can be measured by the ratio between the tip blade speed and wind speed which can be called tip speed ratio $\lambda$. If $\omega$ is the angular frequency of wind turbine, then the expression of tip speed ratio $\lambda$ shown as (15).

$$
\lambda=\frac{\omega R}{v}
$$

The power coefficient $C_{p}$ reflects the size of capturing the power from natural wind, which is an important parameter to characterize efficiency of wind energy utilization. If the wind speed is a constant, the energy captured by the wind turbine is only relevant with power coefficient $C_{p}$. The larger value of $C_{p}$, the greater active power captured by wind turbine, and the wind energy conversion efficiency is higher. Figure 4 is the characteristic curve of a wind turbine to capturing the power. It is can be seen from the figure that the power captured by the wind turbine will along the red curve when the wind speed changes.

\section{The Mathematical Model of Double-Fed INDUCTION GENERATOR (DFIG)}

A. The basic structure and working principle of doublefed wind turbine

Double-fed wind power generation system is mainly composed of wind turbine, speed increasing box, DFIG

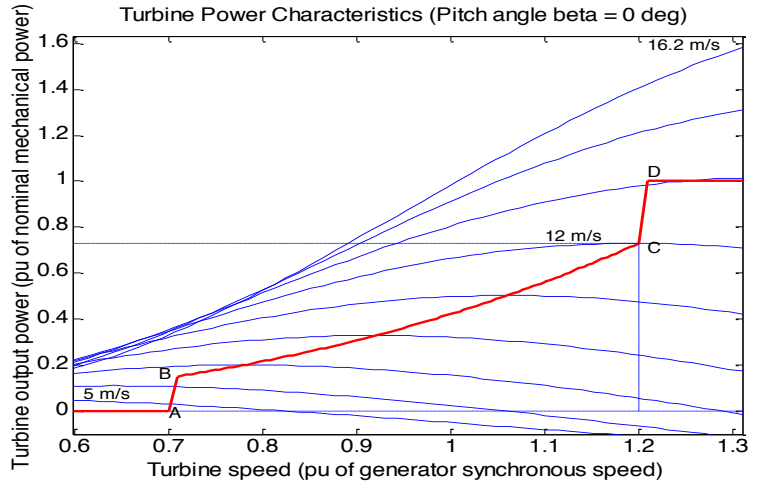

Figure 4. Mechanical power properties of wind turbine

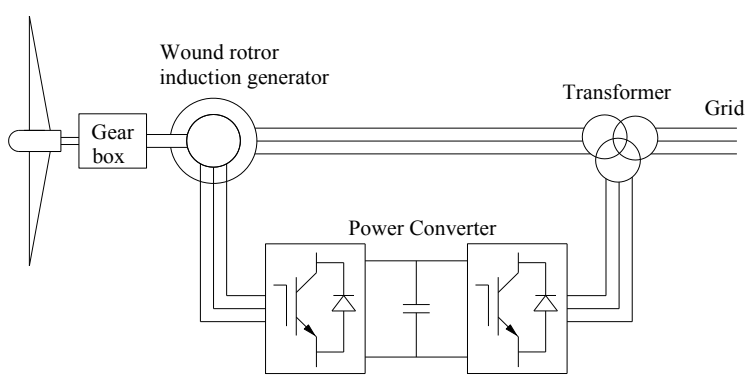

Figure 5. Basic structure of double-fed wind turbine

and back-to-back PWM [11-12], and its structure diagram is shown in figure 5. The stator winding of DFIG is connected directly with power grid, and the rotor winding is connected with power grid through AC-DC-AC converter. When the DFIG is running at different speed, the rotating speed will make appropriate adjustments, so that the wind turbine can always runs at its best state to improve the utilization ratio of wind energy. When the load and rotating speed of double-fed wind turbine have changed, by adjusting the feed current of rotor winding not only can keep the voltage and frequency of stator unchanged, but also can adjust the power factor of the generator.

According to the principle of the rotating magnetic fields generating from the stator and rotor winding of DFIG is relatively static. The relationship between rotating speed of double-fed wind turbine and current frequency of stator and rotor windings can be expressed as (16).

$$
f_{1}=p n / 60 \pm f_{2}
$$

In equation (16), $f_{1}, f_{2}, n$ and $p$ are stator current frequency, rotor current frequency, rotating speed and pole pairs of generator respectively.

It is can be seen from equation (16) that when the rotating speed $n$ changes, in order to maintain $f_{1}$ to be consistent with the grid frequency, the rotor current frequency $f_{2}$ should be adjusted appropriately, which realizes the variable speed constant frequency control of double-fed wind turbine. The back-to-back converter consists of two $\mathrm{AC} / \mathrm{DC}$ voltage source converter based on IGBT, and the DC sides of the two converters are provided voltage support by the common capacitor. If the wind turbine runs at sub-synchronous state, then the equation (16) takes positive sign and the rotor will absorb power from the grid by the converter. If the wind turbine runs at supersynchronization state, then the equation (16) takes negative sign and the power flowed into the grid by the converter as well. The bidirectional flow of the active and the 
reactive power from the machine side to the grid side have been realized.

\section{B. The basic mathematical model of DFIG}

In the model of DFIG, the stator winding uses generator convention while the rotor winding uses motor convention. The basic equations of DFIG in the $d q$ coordinate system have been given in [13-14].

The flux equations of stator and rotor winding are shown in equation (17).

$$
\left\{\begin{array}{l}
\psi_{d s}=-L_{s} i_{d s}+L_{m} i_{d r} \\
\psi_{q s}=-L_{s} i_{q s}+L_{m} i_{q r} \\
\psi_{d r}=L_{r} i_{d r}-L_{m} i_{d s} \\
\psi_{q r}=L_{r} i_{q r}-L_{m} i_{q s}
\end{array}\right.
$$

The voltage equations of stator and rotor winding are shown in equation (18).

$$
\left\{\begin{array}{l}
u_{d s}=-R_{s} i_{d s}-p \psi_{d s}+\omega_{1} \psi_{q s} \\
u_{q s}=-R_{s} i_{q s}-p \psi_{q s}-\omega_{1} \psi_{d s} \\
u_{d r}=R_{r} i_{d r}+p \psi_{d r}-\omega_{s} \psi_{q r} \\
u_{q r}=R_{r} i_{q r}+p \psi_{q r}+\omega_{s} \psi_{d r}
\end{array}\right.
$$

The equations of instantaneous active and reactive power of stator winding are shown in equation (19).

$$
\left\{\begin{array}{c}
P_{s}=\operatorname{Re}\left(\dot{U}_{s} \dot{I}_{s}^{*}\right)=u_{d s} i_{d s}+u_{q s} i_{q s} \\
Q_{s}=\operatorname{Im}\left(\dot{U}_{s} \dot{I}_{s}^{*}\right)=u_{q s} i_{d s}-u_{d s} i_{q s}
\end{array}\right.
$$

The equations of instantaneous active and reactive power of rotor winding are shown in equation (20).

$$
\left\{\begin{array}{c}
P_{s}=\operatorname{Re}\left(\dot{U}_{r} \dot{I}_{r}^{*}\right)=u_{d r} i_{d r}+u_{q r} i_{q r} \\
Q_{s}=\operatorname{Im}\left(\dot{U}_{r} \dot{I}_{r}^{*}\right)=u_{q r} i_{d r}-u_{d r} i_{q r}
\end{array}\right.
$$

The equations (17)-(20) are the basic equations of DFIG. Among them the subscript $s, r$ stand for the stator and rotor respectively, $L_{s}, L_{r}$, and $L_{m}$ stand for stator inductance, rotor inductance, and mutual inductance between the stator and rotor respectively. $\omega_{1}$ and $\omega_{s}$ are synchronous angular speed and slip angular velocity respectively.

\section{CASE STUdy}

Figure 6 is the distribution of a wind farm which has 15 wind turbines, and the asterisk represents the wind turbine. The type of the turbines is GE $1.5 \mathrm{~s}$, and its output power is $1.5 \mathrm{MW}$. The rotor diameter of wind turbine is $70.5 \mathrm{~m}$, and the height of the tower is $67 \mathrm{~m}$.

According to the content described above, the wind speed at the wind turbine installation points can be obtained by calculating the flow field of the wind farm. The calculated wind speed is shown in figure 7, and the computation time of the wind speed is $300 \mathrm{~s}$. Where the red line is the wind speed measured by mast, the other wind speed have been calculated considering the influence of terrain and wake. It is can be known from figure 7 that the wind speeds at the wind turbine installation points are different because of the influence of terrain and wake.

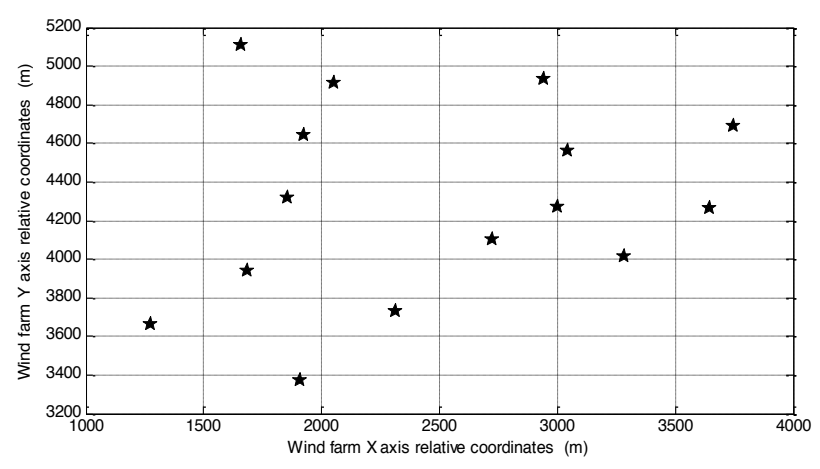

Figure 6. The wind farm for study

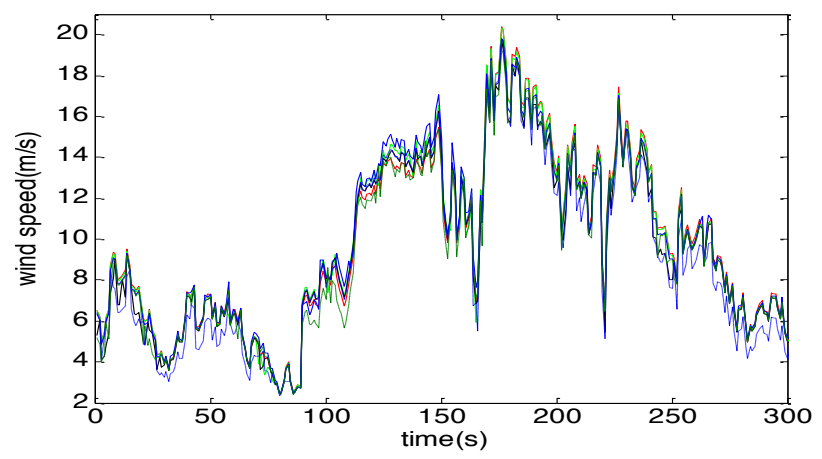

Figure 7. Wind speed at the wind turbine installation points

The wind speeds at the wind turbine installation points are selected as input wind speed and the production process of the wind farm has been simulated and analyzed. The production process of the wind farm is compared with the single input speed modeling method.

Figure 8 is the active power output diagram of the wind farm based on the two modeling methods above, where the solid line corresponds to the mode of single input wind speed taking the wind speed measured by mast as an input, while the dotted line corresponds to the mode of actual wind speed at each wind turbine installation points as an input. Figure 8 shows that there is some difference of the output active power between two modeling methods, but the difference is not very significant, this mainly because that the selected wind farm has relatively flat terrain and the space between turbines is larger, so that the terrain and wake have less effect on wind speed, which leads to the output power of the two modeling methods are relatively similar.

But on the local details the single input speed modeling method is affected easily by the wind speed changes, while the equivalent modeling method proposed is affected relatively small by the wind speed changes. That is mainly because there are different wind speeds at wind turbine installation points, and the sum of their output power has some smoothing effect which leading to the output power of the whole wind farm is smoother, it is consistent with the actual wind farm operation.

Figure 9 is the reactive power output diagram of the wind farm, where the solid line corresponds to taking the wind speed measured by mast as an input for the wind farm modeling method, while the dotted line corresponds to the mode of actual wind speed at each wind turbine installation point as an input. It is can be seen from the reactive comparison chart that there is a larger fluctuation of the reactive power when using the mast wind speed as 


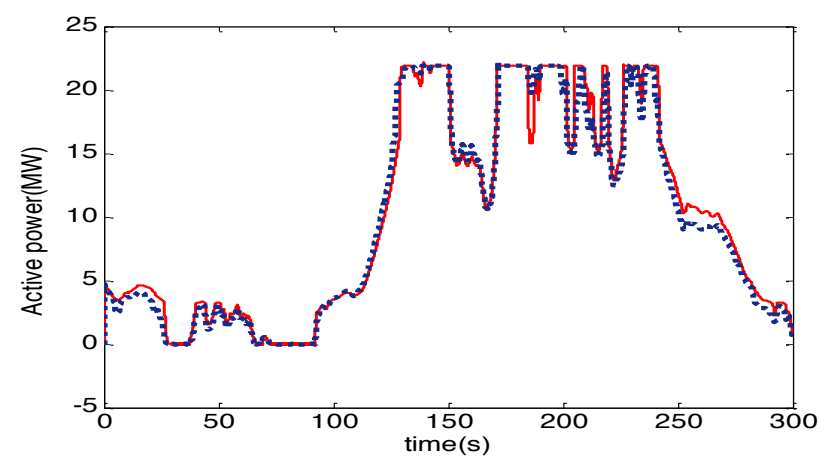

Figure 8. Active power comparison of two equivalent models

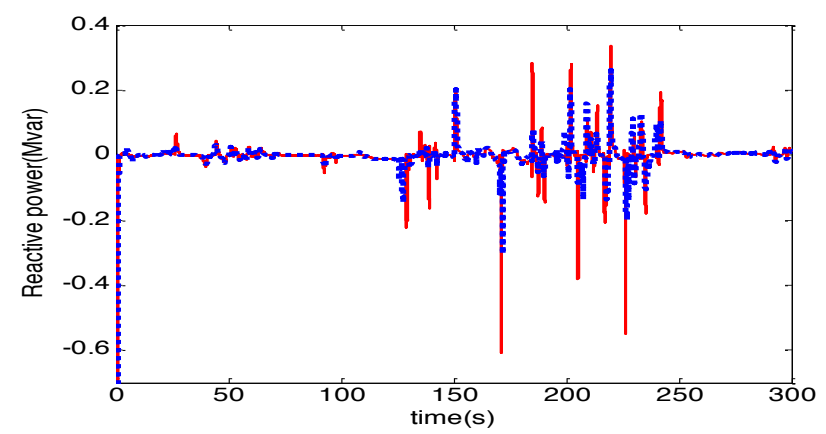

Figure 9. Reactive power comparison of two equivalent models

an input. That is mainly because the wind farm modeling method selected the mast wind speed as an input is affected easily by the wind speed changes. While the wind farm modeling method selected the actual wind speed at each wind turbine installation point as an input has smoothing effect when wind speed changes.

\section{CONCLUSIONS}

An equivalent modeling method for double-fed wind farm based on flow field characteristics has been proposed in this paper. This method takes the influence of terrain and the wake into account when modeling the double-fed wind farm, the calculation model of the flow field in the wind farm has been established, and the calculation model is used to calculate the wind speed at each wind turbine installation point. The wind speed at each wind turbine installation point is inputted into wind turbines model, the dynamic characteristics of the wind farm in the production process has been researched. The simulation results show that the modeling method based on flow field characteristics accurately describes the smoothing effect when the wind speed is changing, and truly reflects the dynamic characteristics of the wind farm in production process.

\section{REFERENCES}

[1] Hongguang Zhang, Lizi Zhang, Shuyong Chen, etc. "Studies on the transient behavior and dispatching strategy of power system integrated with large scale wind farms", Proceeding of the CSEE, 2007, Vol. 27, Issue 31, pp. 45-51.

[2] Hongliang Guan, Yongning Chi, Huizhu Dai, etc. "Small signal stability and control of wind turbine with asynchronous generator integration into power system", Automation of electric power systems, 2008, Vol. 32, Issue 4, pp. 54-59.

[3] Xiaoliang Han, Shaojun Sun, Yanjun Du, etc. "Effects of map precision on calculation of power for wind farms over the rugged terrain”, Power system and clean energy, 2012, Vol. 28, Issue 12, pp. 84-86.

[4] David A. Spera. "Wind Turbine Technology Fundamental Concepts of Wind Turbine Engineering", New York: ASME, 1994, pp. 313-315.

[5] Ekanayake. Janaka B, Holdsworth Lee, Wu Xueguang, ect. "Dynamic Modeling of Doubly Fed Induction Generator Wind Turbines", IEEE Transactions on power systems, 2003, Vol. 18, Issue 2, pp. 803-809.

[6] Hui Li, Hesheng Wang, Xuyang Shi, etc. "Study on equivalent model of wind farms based on genetic algorithm", Power system protection and control, 2011, Vol. 39, Issue 11, pp. 1-8.

[7] Ran Li, Fan Tang, Yingpei Liu, etc. "Equivalent model of doublyfed wind turbine generator systems based on auto mutation particle swarm optimization algorithm", Automation of electric power systems, 2012, Vol. 36, Issue 4, pp. 22-27.

[8] Sten Frandsen, Morten L. Thøgersen. "Integrated fatigue loading for wind turbines in wind farms by combining ambient turbulence and wakes", Wind Engineering, 1999, Vol. 23, Issue 7, pp. 327340.

[9] Katic I., Hojstrup J. and Jensen N. O. "A simple model for cluster efficiency", European Wind Energy Conference, Rome, 1986, pp. 407-410.

[10] Jincheng Huang, Ping Yang. "An optimize maximum power point tracking algorithm for small scale wind power generator", Electric machines and control application, 2011, Vol. 38, Issue 3, pp. 4448.

[11] Pena R., Clare J.C., Asher, G.M. "Doubly fed induction generator using back-to-back PWM converters and its application to variable-speed wind-energy generation", IEE Proc., Electric. Power Appl., 1996, Vol. 143, Issue 3, pp. 231-241.

[12] Muller S, Deicke M, De Doncker R.W. "Doubly fed induction generator systems for wind turbines", IEEE Ind. Appl. Mag., 2002, Vol. 8, Issue 3, pp. 26-33. http://dx.doi.org/ $\underline{10.1109 / 2943.999610}$

[13] A. L. Olimpo, J. Nick, E. Janaka, C. Phil and C. Michael. "Wind Energy Generation: Modeling and Control", A John Wiley and Sons, Ltd, New York, USA, 2009.

[14] Yunqi Xiao. "Research on excitation control and optimal operation for doubly-fed wind power generator", Beijing: North China electric power university, 2008.

\section{AUTHORS}

Gu Bo Author received the Master degree in North China Institute of Water Conservancy and Hydroelectric Power in 2006. Currently, he is a lecturer at North China University of Water Resources and Electric power. His interests are in new energy generation technologies. (email: gb1982@ncwu.edu.cn).

Submitted 15 June 2014. Published as resubmitted by the authors 25 October 2014. 